ORIGINAL ARTICLE

\title{
Diazepam actions in the VTA enhance social dominance and mitochondrial function in the nucleus accumbens by activation of dopamine D1 receptors
}

\author{
MA van der Kooij ${ }^{1,3,4}$, F Hollis ${ }^{1,3,5}$, L Lozano ${ }^{1}$, I Zalachoras ${ }^{1}$, S Abad ${ }^{1}$, O Zanoletti ${ }^{1}$, J Grosse ${ }^{1}$, I Guillot de Suduiraut ${ }^{1}$, C Canto ${ }^{2}$ and \\ C Sandi ${ }^{1}$
}

Benzodiazepines can ameliorate social disturbances and increase social competition, particularly in high-anxious individuals. However, the neural circuits and mechanisms underlying benzodiazepines' effects in social competition are not understood. Converging evidence points to the mesolimbic system as a potential site of action for at least some benzodiazepine-mediated effects. Furthermore, mitochondrial function in the nucleus accumbens (NAc) has been causally implicated in the link between anxiety and social competitiveness. Here, we show that diazepam facilitates social dominance, ameliorating both the competitive disadvantage and low NAc mitochondrial function displayed by high-anxious rats, and identify the ventral tegmental area (VTA) as a key site of action for direct diazepam effects. We also show that intra-VTA diazepam infusion increases accumbal dopamine and DOPAC, as well as activity of dopamine D1- but not D2-containing cells. In addition, intra-NAc infusion of a D1-, but not D2, receptor agonist facilitates social dominance and mitochondrial respiration. Conversely, intra-VTA diazepam actions on social dominance and NAc mitochondrial respiration are blocked by pharmacological NAc micro-infusion of a mitochondrial complex I inhibitor or an antagonist of D1 receptors. Our data support the view that diazepam disinhibits VTA dopaminergic neurons, leading to the release of dopamine into the NAc where activation of D1-signaling transiently facilitates mitochondrial function, that is, increased respiration and enhanced ATP levels, which ultimately enhances social competitive behavior. Therefore, our findings critically involve the mesolimbic system in the facilitating effects of diazepam on social competition and highlight mitochondrial function as a potential therapeutic target for anxiety-related social dysfunctions.

Molecular Psychiatry (2018) 23, 569-578; doi:10.1038/mp.2017.135; published online 20 July 2017

\section{INTRODUCTION}

High anxiety levels are frequently associated with alterations in individuals' social behaviors. ${ }^{1}$ Emerging evidence indicates that this is particularly the case in competitive settings, where anxious individuals frequently show reduced competitiveness ${ }^{2-4}$ and consequently adopt a subordinate status. ${ }^{5}$ This notion is in line with the increased risk to develop psychopathologies by highanxious individuals ${ }^{6}$ as lower rank in society and social organizations has been related to impaired physical and mental health. ${ }^{7-9}$

Benzodiazepines, the prototypic wide-spectrum anxiolytic drugs, have long been shown to effectively increase social competitiveness in a range of species (from non-human primates $^{10}$ and rodents ${ }^{11}$ to pigeons ${ }^{12}$ ). However, the neural circuits and mechanisms whereby benzodiazepines affect social competition are largely unknown. Given the various side effects, particularly those of habituation and addiction, associated with the long-term use of benzodiazepines, ${ }^{13}$ understanding the neurobiological processes whereby benzodiazepine treatment influences social behaviors could further the design of less harmful therapeutic solutions for anxiety-related deficits in the social domain.
Converging evidence points to the mesolimbic system as a potential site of action for the facilitating effect of benzodiazepines in social dominance. First, benzodiazepines have been shown to act at the ventral tegmental area (VTA), where they are believed to mediate their addictive effects. ${ }^{14}$ Specifically, through positive modulation of the $\Upsilon$-aminobutyric acid type $A$ receptors (GABAaRs) and the consequent disinhibition of dopamine neurons, benzodiazepine actions in the VTA were shown to increase dopaminergic function in the nucleus accumbens (NAc). ${ }^{14-16}$ This is in agreement with early evidence that activation of VTA GABAaRs increases DA release in the NAc. ${ }^{17}$ Secondly, the VTA to the NAc neural-particularly dopaminergic-projections have been implicated in a variety of behavioral processes that likely contribute to the establishment of social dominance, from reward processing to different aspects of behavioral activationincluding motivation, exertion of effort, seeking and energy expenditure and 'vigor' of behavior. ${ }^{18-24}$ Third, the NAc appears to be critically activated in social competitive settings, as shown for human- ${ }^{25-27}$ and non-human primates ${ }^{28,29}$ and for rodents. ${ }^{4,30}$ Furthermore, we recently established a causal role for mitochondrial function in the NAc linking anxiety and social competition. ${ }^{4}$

\footnotetext{
${ }^{1}$ Laboratory of Behavioral Genetics, Brain Mind Institute, École Polytechnique Fédérale de Lausanne (EPFL), Lausanne, Switzerland and ${ }^{2}$ Nestlé Institute of Health Sciences SA, Lausanne, Switzerland. Correspondence: Professor C Sandi, Brain Mind Institute, École Polytechnique Fédérale de Lausanne (EPFL), Station 19, Lausanne CH-1015, Switzerland. E-mail: carmen.sandi@epfl.ch

${ }^{3}$ These authors contributed equally to this work.

${ }^{4}$ Current address: Johannes Gutenberg University Medical Centre, Department of Psychiatry and Psychotherapy and Focus Program, Translational Neurosciences, Mainz 55128, Germany.

${ }^{5}$ Current address: Université de Lausanne, Department of Fundamental Neuroscience, Lausanne $\mathrm{CH}-1005$, Switzerland.

Received 17 April 2016; revised 10 May 2017; accepted 15 May 2017; published online 20 July 2017
} 
Here, we investigated whether diazepam can enhance social competition through direct actions in the VTA and explored downstream mechanisms of action, particularly mitochondrial respiration and the accumbal dopaminergic system. Our data demonstrate the ability of diazepam to facilitate social dominance-including the reversal of the competitive disadvantage displayed by high-anxious animalsand enhance mitochondrial function in the NAc in rats in a D1 receptor-dependent manner. Our findings implicate increased dopamine release from the VTA along with the engagement of NAc D1 receptors in the NAc in these facilitating effects.

\section{MATERIALS AND METHODS}

Animals

Adult male Wistar rats (Charles River, L'Arbresle, France) weighing 250$275 \mathrm{~g}$ at the start of experiments were used. Animals were individually housed in polypropylene cages $(57 \times 35 \times 20 \mathrm{~cm})$ with abundant pine bedding in a temperature- $\left(23^{\circ} \mathrm{C}\right)$ and light- (lights on from 0700 to 1900 hours) controlled room. All animals had ad libitum access to standard food and water. Upon arrival to the facility, animals were allowed to habituate to the vivarium for 1 week and were then handled for $2 \mathrm{~min} /$ day during 3 days before the start of all experiments. All behavioral manipulations were performed during the light phase by experimenters blind to treatment groups. All experiments were performed with the approval of the Cantonal Veterinary Authorities (Vaud, Switzerland) and carried out in accordance with the European Communities Council Directive of 22 September 2010 (2010/63/EU).

The elevated plus maze, intracerebral surgery, pharmacology, social preference test, social dominance test, mitochondrial respirometry, highperformance liquid chromatography, microdialysis, immunohistochemistry, as well as protein, mtDNA and gene expression were all performed following the procedures detailed in the Supplementary Materials and Methods. All efforts were made to minimize the number of animals while maintaining statistical rigor.

\section{Statistical analyses}

Samples sizes $(N)$ are indicated in figure legends and represent biological replicates only. Sample sizes were based on pilot experiments and our previous work. ${ }^{4}$ Animals were characterized (depending on the experiment) and randomly allocated to groups. Investigators were blinded to the groups during the experiment and assessment. Unpaired two-tailed student's $t$-tests were used to compare sets of data obtained from independent groups of animals except for the correlational data between mitochondrial complex activity and social dominance (Supplementary Figure 4), where we had a priori expectations regarding linkage direction. Within-pair amounts of behavior in the social dominance test were compared using paired two-tailed student's $t$-tests. In sets of data in which animals were matched for anxiety, relative social dominance scores were compared using one-sample $t$-tests against chance (50\%). In sets of data in which comparisons were performed against the vehicle-treated control, data from experimental animals were normalized to control values and compared using one-sample $t$-tests. All data had similar variances apart from protein kinase A (PKA) phosphorylated protein data (Figure 2j), which was analyzed using a Welch's correction. All data-except for mitochondrial respiration-were analyzed using Prism version 5.01 (Graphpad Software, San Diego, CA, USA) and are presented as the mean \pm s.e.m. For respiration experiments, data were analyzed using SPSS statistical software version 13.0 (SPSS, Chicago, IL, USA). As experiments were performed in blocks across days, a linear mixed model was created that included block as a random effect in addition to fixed effects of either anxiety or treatment (depending on the experiment). Data from respiration experiments are presented as estimated marginal means with s.e.m. Statistical significance was considered at the $P<0.05$ level.

\section{RESULTS}

Diazepam actions in the VTA facilitate social competition and mitochondrial respiration in the NAC

We first studied the effects of an intra-VTA DZP infusion on behavioral and metabolic outcomes examined $30 \mathrm{~min}$ post treatment compared to vehicle-treated animals matched for equivalent anxiety levels (Figure 1a). Intra-VTA DZP at a dose (25 ng per hemisphere) that effectively reduced anxiety-like behavior (Figure 1b) without affecting total locomotor activity (Supplementary Figures $1 \mathrm{a}$ and $\mathrm{b}$ ) in the elevated plus maze, enhanced social dominance in a social competition test (Figure 2c). However, this treatment did not affect social exploration in the social preference test (Supplementary Figure 1c).

The same intra-VTA DZP treatment, given to new cohorts of animals, led to an increase in mitochondrial respiration in the NAC (Figure 1d), while mitochondrial respiration in the VTA was not affected (Figure 1e). This increase in respiration was not due to an increase in mitochondrial content as quantitative PCR with reverse transcription analyses of mitochondrial DNA (mtDNA) copy number of NADH dehydrogenase subunits ND1 and ND4 indicated no differences in NAc mtDNA content between DZP- and vehicletreated animals (Figure 1f). Furthermore, the observed increase in respiration seems not to be the result of uncoupling effects of DZP on NAc mitochondria, as DZP-treated animals did not show any change in the mRNA levels of uncoupling markers, such as uncoupling protein 2 , in the NAc or medial prefrontal cortex (mPFC; Supplementary Figure 2). Instead, DZP treatment led to significantly enhanced ATP levels specifically in the NAc (Figure 1g), supporting the view that the DZP-induced increase in mitochondrial respiration is functional. Interestingly, when DZP was infused directly into the NAc (Supplementary Figure 3a), there were no effects on behavioral (Supplementary Figures $3 \mathrm{~b}$ and $\mathrm{c}$ ) or metabolic (Supplementary Figure 3d) measures, suggesting that the DZP-induced effects on the NAc region are directly engendered by the VTA projections, rather than through local alterations at the VTA itself. As several studies have implicated the dopaminergic pathway in social behaviors and motivation, ${ }^{31,32}$ and the dopaminergic projection is one of the major projections from the VTA to the NAc, we hypothesized that the DZP-induced effects on the NAc might involve changes in dopamine release. Supporting a role for the induction of accumbal DA release in the effects of DZP, intra-VTA DZP infusion increased levels of dopamine and 3,4dihydroxyphenylacetic acid (DOPAC) in the NAc (Figure $1 \mathrm{~h}$ and Supplementary Figure 4) but not in other dopaminergic VTA-output regions (Supplementary Figure 5).

To determine whether the link between VTA-NAc social competition and mitochondrial respiration is functional, we examined whether the effects of intra-VTA DZP could be prevented by inhibiting mitochondrial respiration in the NAc. We reduced mitochondrial respiration by infusing a low dose ( $10 \mathrm{ng}$ per $0.3 \mathrm{ul}$ ) of the mitochondrial complex I inhibitor, rotenone, into the NAc immediately prior to DZP infusion into the VTA. Although rotenone infusion alone did not affect social competition, pre-infusion of rotenone prevented the enhancing effects of intra-VTA DZP on social competition (Figure 1i), suggesting a causal involvement of NAc mitochondrial function in the actions exerted by DZP infusions in the VTA on social competition. In addition, and in support of this causal implication, we found in another cohort previously submitted to social competition that NAc mitochondrial respiratory measures correlated positively with their social dominance scores (Supplementary Figure 6).

Involvement of NAc D1 receptors in intra-VTA DZP effects on social competition and mitochondrial respiration

Given the DA release induced by DZP treatment (see Figure $1 \mathrm{~h}$ ), we next examined whether intra-VTA DZP would activate specific dopamine receptor-containing neurons in the NAc. DZP treatment led to an enhancement of cFOS protein expression in D1-, but not D2-containing neurons in the NAc (Figure 2a-c). The same treatment did not induce changes in CFOS expression in specific dopaminoceptive neurons in other VTA dopaminergic projection regions, such as the $\mathrm{mPFC}$ and basolateral amygdala (BLA; Supplementary Figure 7). We then tested the relevance of DA activation in the NAc for social competition and mitochondrial 


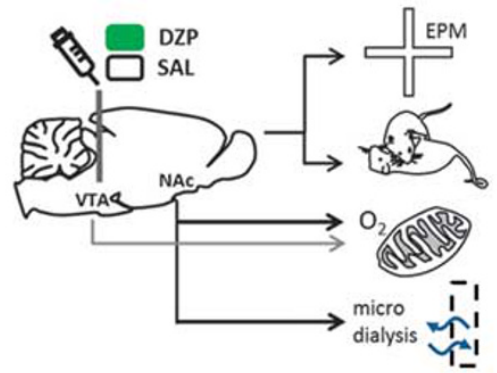

b

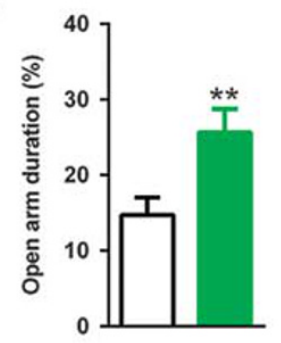

C

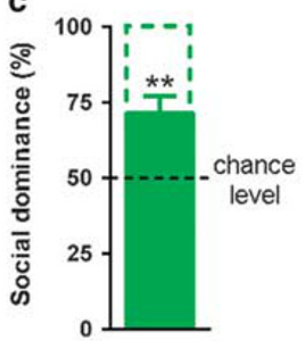

d

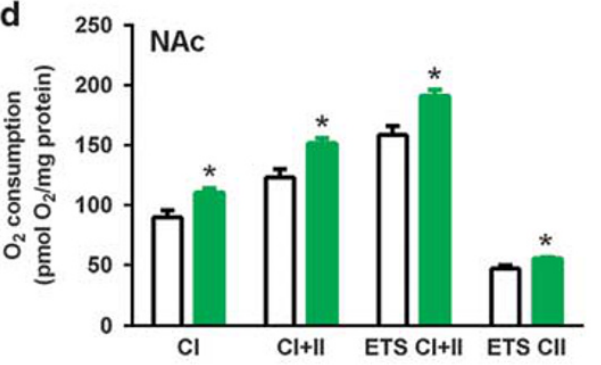

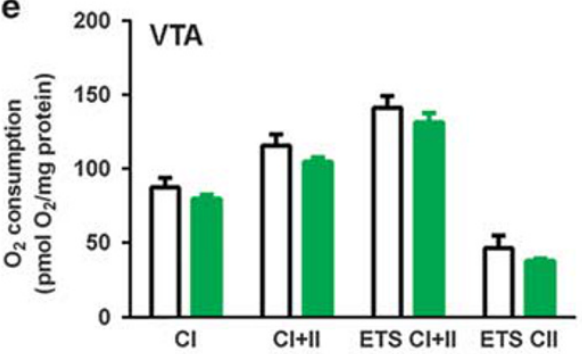

f

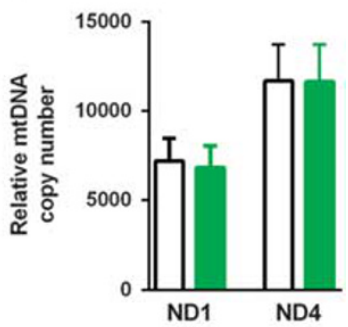

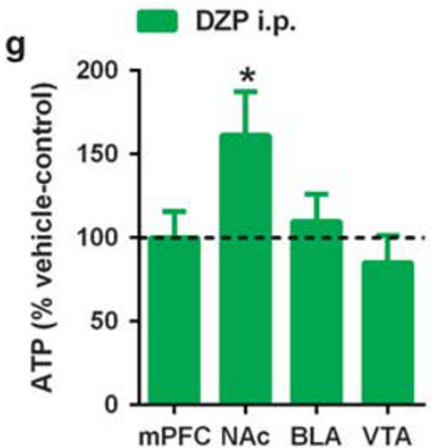
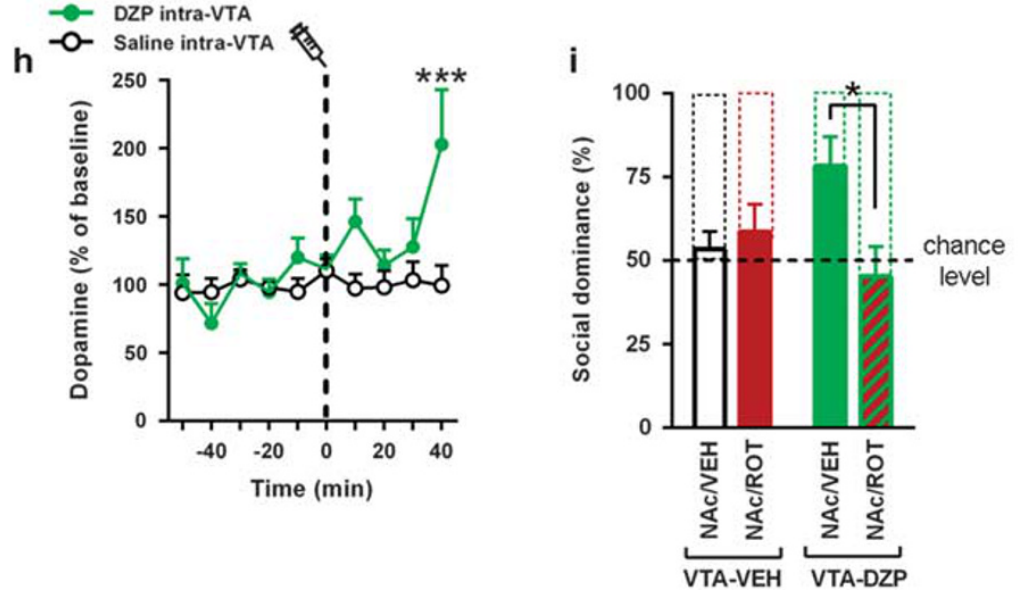

Figure 1. DZP infused into the VTA reduces anxiety, and enhances social competition and mitochondrial respiration of the NAc. The effects of intra-VTA DZP or vehicle (saline, (SAL)) were studied on anxiety-like behavior on the EPM, social competition and the nucleus accumbens was examined for mitochondrial respiration and neurotransmitter release using microdialysis (a). Intra-VTA administration of DZP $(N=23$ SAL, 13 DZP) had an anxiolytic effect, increasing time spent on the open arms of the EPM $(\mathbf{b}),(t=2.88, \mathrm{df}=34, P=0.007)$ and increased social competition for anxiety-matched animals ( $N=15$ pairs) above chance level $(\mathbf{c}),(t=3.81, \mathrm{df}=14, P=0.002)$. This treatment $(N=4 / \mathrm{group})$ also enhanced mitochondrial respiration in the NAc $\left((\mathbf{d})\right.$ complex I $\left[\mathrm{F}_{(1,6)}=8.88 ; P=0.025\right]$, complex I+II $\left(\mathrm{F}_{(1,6)}=11.85 ; P=0.014\right)$, ETS $\left(\mathrm{F}_{(1,6)}=12.14\right.$; $P=0.013)$, ETS CII $\left(F_{(1,6)}=7.43 ; P=0.03\right)$ ). Intra-VTA DZP did not affect mitochondrial respiration of the VTA as compared to vehicle (saline $(\mathrm{SAL})$ ) injected controls $(\mathbf{e})$, (complex I $\left(\mathrm{F}_{(1,6)}=1.23 ; P=0.31\right)$, complex I+II $\left(\mathrm{F}_{(1,6)}=1.79 ; P=0.23\right)$, ETS $\left(\mathrm{F}_{(1,6)}=0.925 ; P=0.37\right)$, ETS CII $\left(\mathrm{F}_{(1,6)}=1.02\right.$; $P=0.35), N=4 /$ group)) or mtDNA copy number levels for ND1 (f) $(t=0.211, \mathrm{df}=20, P=0.85, N=10 \mathrm{SAL}, N=12 \mathrm{DZP}))$ or ND4 (f), $(t=0.015$, $\mathrm{df}=20, P=0.99, N=10 \mathrm{SAL}, N=12 \mathrm{DZP})$ ). DZP or vehicle (saline, SAL) was i.p. injected after which the mPFC, NAc, BLA and VTA were taken out by microdissection. ATP levels were increased only in the NAc $(\mathbf{g}), \operatorname{mPFC}(t=0.01, \mathrm{df}=12, P=0.99) ; \mathrm{NAc}(t=2.366, \mathrm{df}=10, P=0.03, N=13 \mathrm{SAL}$, $N=11$ DZP); BLA $(t=0.61, \mathrm{df}=12, P=0.92))$. Intra-VTA DZP increased the accumbal levels of accumbal dopamine, (h), treatment effect $\mathrm{F}_{(1,7)}=8.55, P=0.022$ with post test at $\left.40 \mathrm{~min} t=4.29, P<0.001\right)$. The effects of intra-VTA DZP could be blocked by intra-NAc pre-infusion with rotenone (ROT) (i, interaction effect $\left[F_{(1,43)}=4.59, P=0.038\right]$ with post test DZP-VEH vs DZP-ROT $(t=2.54, \mathrm{df}=43, P=0.015)$ ). Data are mean \pm s.e.m. $\left({ }^{*} P<0.05\right.$, ${ }^{* *} P<0.01,{ }^{* *} P<0.001$, unpaired Student's $t$-test (b and $\mathbf{f}$ ), one-sample $t$-test against chance level (c), or against vehicletreated controls $(\mathbf{g})$ or two-way ANOVA with repeated measures (h) and without (i)). Respiration data (d and e) are presented as estimated marginal means + s.e.m. of oxygen flux per $\mathrm{mg}$ tissue $\left({ }^{*} P<0.05\right.$, linear mixed model). See also Supplementary Figures $1-6$. ANOVA, analysis of variance; BLA, basolateral amygdala; DZP, diazepam; EPM, elevated plus maze; mPFC, medial prefrontal cortex; NAc, nucleus accumbens; VAT, ventral tegmental area.

respiration by micro-infusing D1 and D2 receptor agonists (Figure 2d). Intra-NAc infusion of the D1 receptor agonist SKF-38393 (300 ng per hemisphere) increased social competition whereas intra-NAc infusion of the D2 receptor agonist quinpirole had no effect (Figure 2e). We verified that the selected quinpirole dose is effective under our experimental conditions by confirming its formerly reported locomotor effects ${ }^{33}$ in the open field
(Supplementary Figure 8). Thus, these observations are in line and expand our previous findings that social competition invokes a specific activation of D1-containing cells in the NAC that positively correlates with the amount of offensive behavior exerted. ${ }^{4}$ Furthermore, we found that intra-NAc infusion of the D1 receptor agonist SKF-38393 (300 ng/hemisphere) increased mitochondrial respiration in the NAc (Figure $2 f$ ). 
a

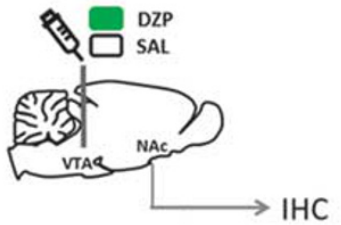

d

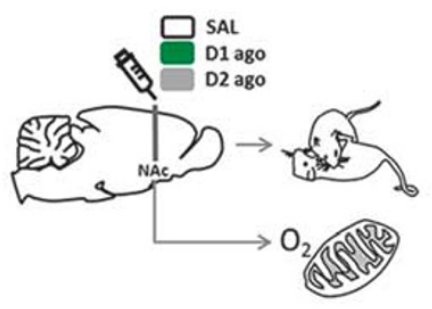

g

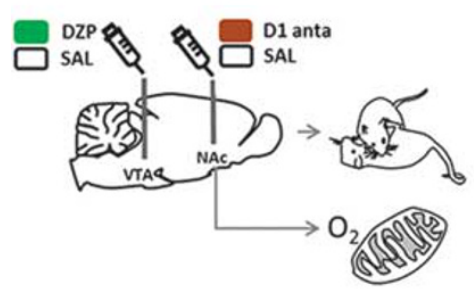

b

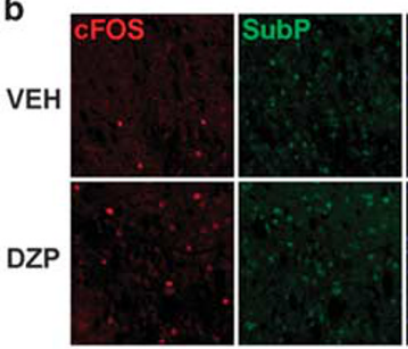

e

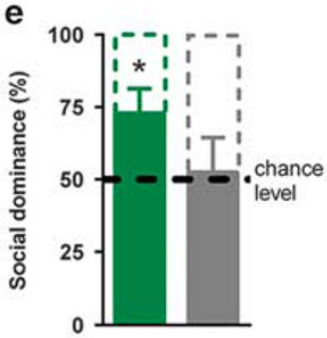

h

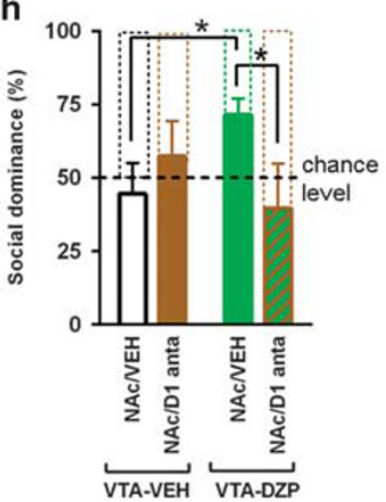

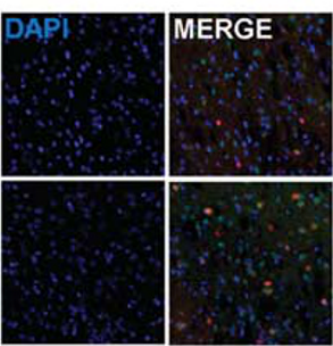

C

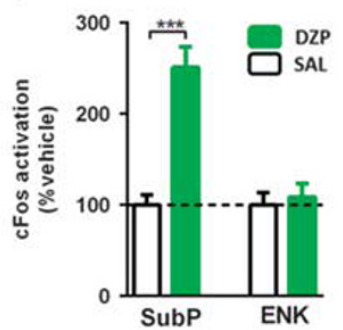

f

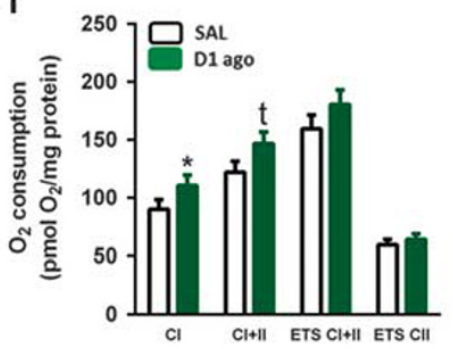

i

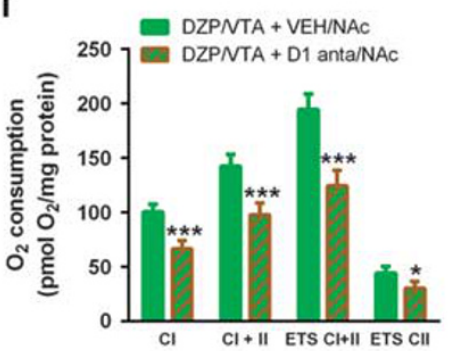

j

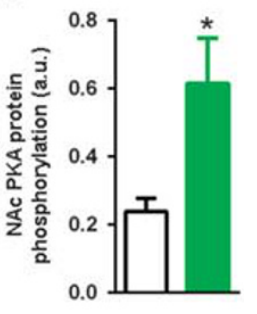

Figure 2. The dopamine D1 receptor in the NAc is critical for the expression of social competition. Intra-VTA infusion of DZP (a) led to significant cFOS protein activation of D1-, but not D2-containing neurons in the NAc (b and c) D1 ${ }^{+}(t=6.18, \mathrm{df}=17, P<0.0001, N=10 \mathrm{SAL}$, $N=9 \mathrm{DZP}), \mathrm{D}^{+}(t=0.433, \mathrm{df}=18, P=0.67, N=10 \mathrm{SAL}, N=10 \mathrm{DZP})$. Intra-NAc infusion of a D1-like agonist (D1ago, SKF-38393, $300 \mathrm{ng}$ per $0.3 \mu \mathrm{l}$, $N=12$ pairs) increased social competition while a D2-like agonist (D2ago, quinpirole, $300 \mathrm{ng}$ per $0.3 \mu l, N=12$ pairs) had no effects on social competition against vehicle (saline, (SAL)) infused controls (d and e), D1ago: $t=2.69$, df $=11, P=0.02 ; \mathrm{D} 2$ ago: $t=0.61, \mathrm{df}=10, P=0.55$ ). IntraNAc infusion of the D1-like agonist ( $N=14$ D1ago, $N=16 \mathrm{SAL})$ increased mitochondrial respiration of the NAc (d and $\mathbf{f})$, complex I $\left(\mathrm{F}_{(1,22.4)}=11.79 ; P=0.002\right)$, complex I+II $\left.\left(\mathrm{F}_{(1,28)}=7.33 ; P=0.01\right)\right)$. Intra-NAc infusion of the D1-like antagonist $(N=7$ pairs DZP/D1anta) blocked the effect of intra-VTA infusion of diazepam on social competition (VTA-diazepam-bar is replicated from Figure $1 \mathrm{~d}$ for comparison ( $\mathbf{g}$ and $\mathbf{h}$, interaction effect $\left(\mathrm{F}_{(1,40)}=4.63, P=0.038\right)$ with post-tests VTA-VEH/NAc-VEH vs VTA-DZP/NAc-VEH $(t=2.04, P=0.048)$ and VTA-DZP/NAc-VEH vs VTA-DZP/NAC-ROT $(t=2.09, P=0.04))$. The intra-NAc infusion of the D1-like antagonist $(N=4 \mathrm{DZP} / \mathrm{VEH}, N=5 \mathrm{DZP} / \mathrm{D} 1$ anta) also prevented the increase in NAc mitochondrial respiration induced by diazepam infusion into the VAT (VAT ( $g$ and $\mathbf{i})$ complex I $\left(F_{(1,7)}=48.7 ; P<0.0001\right)$, complex I+II $\left(\mathrm{F}_{(1,7)}=38.1 ; P<0.0001\right)$, ETS $\left(\mathrm{F}_{(1,7)}=52.7 ; P<0.0001\right)$, ETS CII $\left.\left(\mathrm{F}_{(1,7)}=10.6 ; P=0.01\right)\right)$. Intra-VTA diazepam infusion significantly increased PKA phosphorylation of NAc proteins ( $\mathbf{j}$, $[\mathrm{t}=2.72, \mathrm{df}=19, P=0.014, N=10 \mathrm{SAL}, N=11 \mathrm{DZP}])$. Data $(\mathbf{c}, \mathbf{e}, \mathbf{h}$ and $\mathbf{j})$ are mean \pm s.e.m. $\left({ }^{\mathrm{t}} \mathrm{p}<0.1,{ }^{*} P<0.05\right.$, ${ }_{* * *}^{*}<0.001$, one-sample $t$-test against chance level (e), unpaired Student's $t$-test (c and $\left.\mathbf{j}\right)$ or two-way ANOVA (h). Respiration data (f, i) are presented as estimated marginal means \pm SEM of oxygen flux per mg tissue $\left({ }^{t} p<0.1,{ }^{*} P<0.05, * * * P<0.001\right.$, Linear Mixed Model). ANOVA, analysis of variance; DZP, diazepam; ETS, electron transport system; NAc, nucleus accumben; PKA, protein kinase A; VTA, ventral tegmental area.

We then explored whether NAC D1 receptors would be necessary for the behavioral and metabolic effects induced by intra-VTA DZP infusion (Figure 2g). We found that the enhancing effects of intra-VTA DZP ( $25 \mathrm{ng}$ per hemisphere) on social competition (Figure $2 \mathrm{~h}$ ) and NAc mitochondrial respiration (Figure 2i) were prevented by intra-NAc infusion of the D1 receptor antagonist SCH-23390 (300 ng per hemisphere).

Next, given the rapid DZP effects observed on mitochondrial respiration and the lack of evidence for changes in mtDNA (see Figure 1f), we measured PKA-mediated protein phosphorylation. We found increased PKA-mediated protein phosphorylation after intra-VTA DZP infusion (Figure 2j). However, no change in total content of several measured mitochondrial proteins (that is, DRP1, mitofusin 1 (Mfn1), mitofusin 2 (Mfn2), complex I NDUFS4 subunit,
C1orf163), including specific phosphorylated isoforms such as phosphorylated Dynamin-related protein (phospho-Drp1), were observed (Supplementary Figure 9).

Trait anxiety is associated with variation in NAc D1 receptors activation and mitochondrial function

As our pharmacological experiments highlighted a role for NAC D1 receptors in both social dominance and mitochondrial respiration, we investigated potential differences in the expression of DA receptors in the NAc between high and low-anxious rats. As shown before, ${ }^{4}$ we first confirmed in a new cohort of animals that high-anxious animals have a disadvantage to win a social competition against low-anxious counterparts (Figures $3 a$ and $b$ ) and exhibit 
a

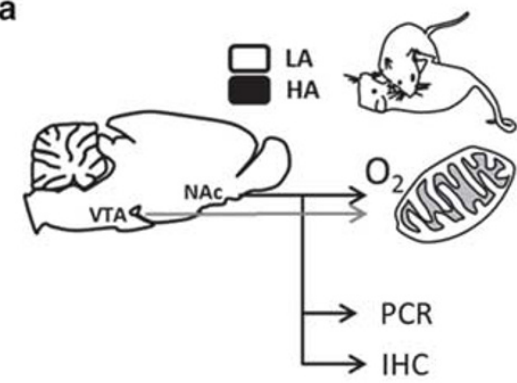

d

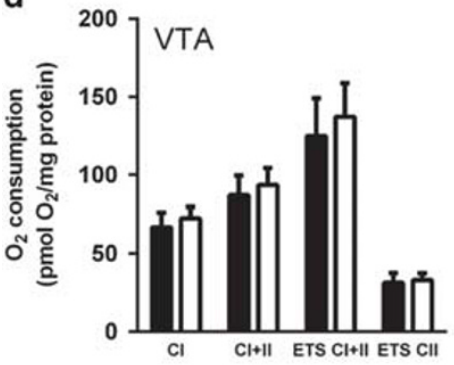

g
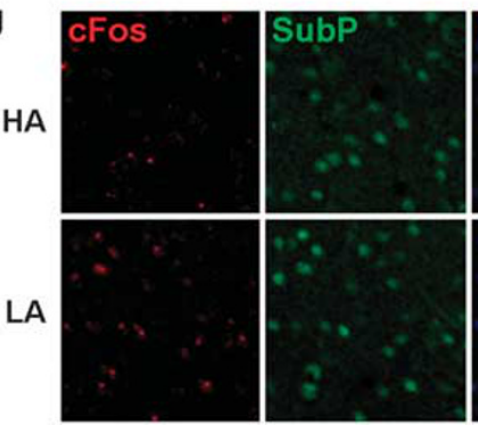

b

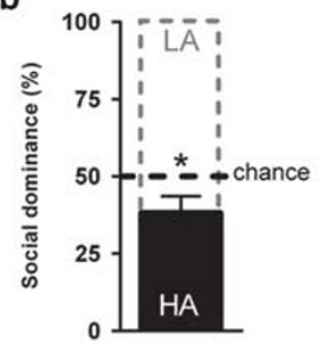

e

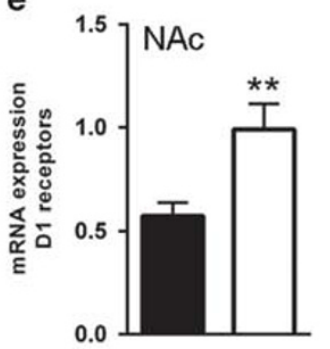

C

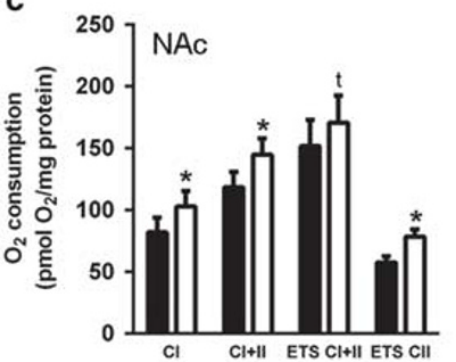

f

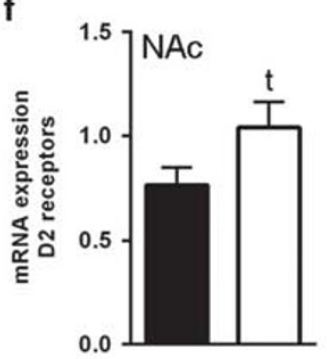

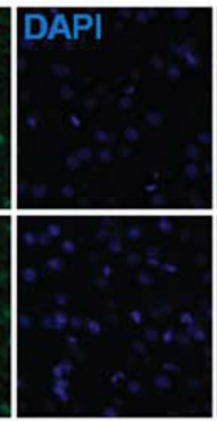

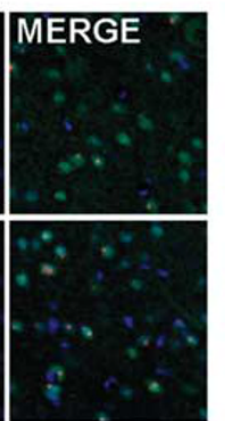

h

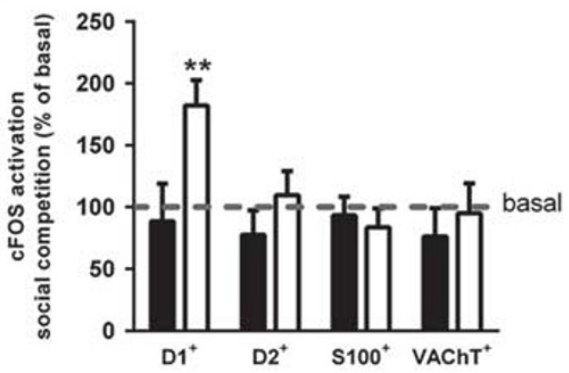

Figure 3. High anxious rats lack activation of D1-receptor expressing cells in the NAc. Social competition, mitochondrial respiration, mRNA expression for the dopamine D1- and D2 receptor and cellular activation using IHC were investigated in HA and LA rats (a). HA express levels of social competition below chance when matched to LA opponents $(N=21$ pairs $)(\mathbf{b}), t=2.24, \mathrm{df}=20, P=0.037)$. HA animals $(N=10)$ exhibit low levels of mitochondrial respiration in the NAc compared to LA counterparts $(N=8)$ under basal conditions $(\mathbf{c})$, complex I $\left(F_{(1,12.9)}=5.87\right.$; $P=0.03)$, complex $I+\| l\left(F_{(1.12 .5)}=7.46 ; P=0.02\right)$, ETS $\left.\left(F_{(1.16)}=8.76 ; P=0.01\right)\right)$, but no differences were observed in the VTA (d, complex I $\left(\mathrm{F}_{(1,10)}=1.34 ; P=0.27\right)$ complex $\mathrm{I}+\mathrm{II}\left(\mathrm{F}_{(1,10)}=0.948 ; P=0.35\right)$ ETS $\left(\mathrm{F}_{(1,9)}=0.902 ; P=0.37\right)$ ETS CII $\left(\mathrm{F}_{(1,9)}=0.284 ; P=0.61\right), N=4 /$ group $)$. HA rats also exhibited lower mRNA levels for the dopamine D1-receptor $(\mathbf{e}, t=3.0, \mathrm{df}=14, P=0.0096)$ and $\mathrm{D} 2$ receptors than $L A$ rats $(\mathbf{f}, t=1.83, \mathrm{df}=15$, $P=0.09, N=8$ /group). Although LA rats $(N=7)$ show increased cFOS protein levels in D1-expressing cells in the NAc upon social competition (g and $\mathbf{h}, t=4.04, \mathrm{df}=6, P=0.007$ ), this increase was not observed for HA animals ( $\mathbf{g}$ and $\mathbf{h}, t=0.38, \mathrm{df}=6, P=0.72, N=7$ ). D2-expressing cells, astrocytes and cholinergic cells were not activated upon social competition in either HA or LA animals. Data (b, e, $\mathbf{f}$ and $\mathbf{g})$ are mean \pm s.e.m. $\left({ }^{t} P<0.1,{ }^{*} P<0.05,{ }^{* *} P<0.01\right.$, one-sample $t$-test against chance- (b) or basal levels (h) or unpaired Student's $t$-test (e and $\left.\mathbf{f}\right)$. Respiration data (c and $\mathbf{d}$ ) are presented as estimated marginal means \pm s.e.m. of oxygen flux per $\mathrm{mg}$ tissue $\left({ }^{\mathrm{t}} P<0.1,{ }^{*} P<0.05\right.$, linear mixed model). See also Supplementary Figure 7. IHC, immunohistochemistry; HA, high-anxious; LA, low-anxious; NAc, nucleus accumbens.

lower levels of mitochondrial respiration in the NAc (Figure 3c) but not in the VTA (Figure 3d) compared to low-anxious animals. Then, using quantitative PCR with reverse transcription, we found significantly lower mRNA expression levels of D1 receptors and a trend for lower levels of D2 receptors in the NAc of high-anxious animals (Figures $3 e$ and f). Subsequently, we compared cellular activation following a social competition challenge with basal activation in the NAc of high and low-anxious rats. For this purpose, we performed triple-labeled immunohistochemical analyses for co-labeled cFOS protein expression and markers for different NAc cellular subtypes. Only D1-containing cells in lowanxious rats following social competition exhibited significantly enhanced cFOS protein activation (Figures $3 g$ and $h$ ). This was not observed in high-anxious rats and neither high- nor low-anxious animals exhibited a competition-induced increase in the activity of D2-containing cells, astrocytes $\left(\mathrm{S} 100^{+}\right)$or cholinergic cells
$\left(\mathrm{VAChT}^{+}\right)$. Altogether, these findings suggest that D1 receptors might be critically implicated in the anxiety-related differences in social competition and NAc mitochondrial respiration.

Diazepam in high-anxious rats enhances social dominance and NAc mitochondrial respiration

Given that diazepam enhanced social dominance, we first tested whether diazepam could revert the disadvantage of high-anxious rats to win a social competition test and then examined the involvement of the NAc in the effects (Figure 4a). Thus, we first injected diazepam systemically at a dose (i.p. $0.5 \mathrm{mg} \mathrm{kg}^{-1}$ ) that reduces anxiety-like behavior in the elevated plus maze (Supplementary Figures 10a-c) without affecting locomotor activity (Supplementary Figure 10d). This treatment given to high-anxious rats increased their social dominance against lowanxious animals well above the low dominance levels observed in 

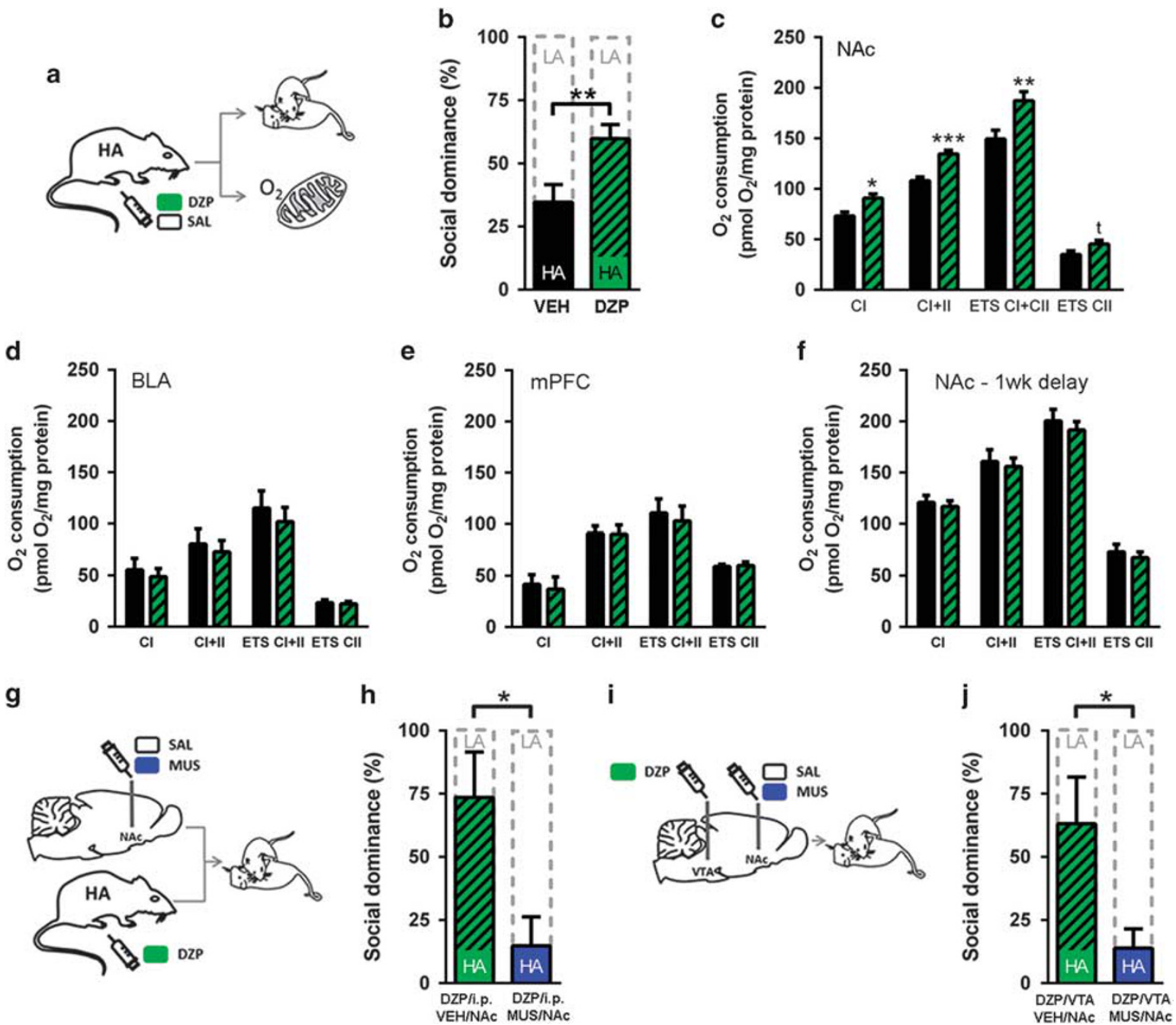

Figure 4. DZP treatment enhances social competition of HA rats and increases mitochondrial respiration of the NAc. DZP $\left(0.5 \mathrm{mg} \mathrm{kg}^{-1}\right.$ i.p.) or vehicle (saline $(S A L)$ ) was administered to HA animals to investigate the effects on social competition and NAc mitochondrial respiration (a). Against social competition with LA rats, vehicle-treated HA rats $(N=19)$ were disadvantaged, while HA animals treated with DZP $(N=20)$ exhibited significantly increased competitiveness $(\mathbf{b}, t=2.80, \mathrm{df}=37, P=0.008)$. This treatment also increased mitochondrial respiration in the NAc of HA rats $\left(N=6 /\right.$ group) (c, complex I $\left[\mathrm{F}_{(1,10)}=9.78 ; P=0.01\right]$, complex I+II $\left[\mathrm{F}_{(1,10)}=25.3 ; P=0.001\right], \mathrm{ETS}\left[\mathrm{F}_{(1,10)}=9.16 ; P=0.01\right]$, ETS CII $[\mathrm{F}(1,10)=3.78 ; P=0.08)$ ) but had no effect on mitochondrial respiration in the BLA (d, (complex I $\left(\mathrm{F}_{(1,10)}=0.224 ; P=0.65\right)$, complex I+II $\left(F_{(1,10)}=0.182 ; P=0.68\right)$, ETS $\left(F_{(1,10)}=0.362 ; P=0.56\right)$, ETS CII $\left.\left(F_{(1,10)}=0.073 ; P=0.79\right)\right), N=6 /$ group $)$ or mPFC (e, (complex I $\left(F_{(1,6)}=0.061\right.$; $P=0.81)$, complex I+II $\left(\mathrm{F}_{(1,6)}=0.003 ; P=0.96\right)$, ETS $\left(\mathrm{F}_{(1,6)}=0.102 ; P=0.76\right)$, ETS Cll $\left.\left(\mathrm{F}_{(1,6)}=0.040 ; P=0.85\right)\right)$, $N=4 /$ group). One week after DZP administration, mitochondrial respiration did not differ from saline-injected $(S A L)$ controls (f, $\left[\right.$ complex I $\left(F_{(1,6)}=0.197 ; P=0.67\right)$, complex I+II $\left(\mathrm{F}_{(1,6)}=0.113 ; P=0.75\right)$, ETS $\left(\mathrm{F}_{(1,6)}=0.417 ; P=0.54\right)$, ETS CII $\left.\left(\mathrm{F}_{(1,6)}=0.364 ; P=0.57\right)\right], N=4 /$ group $)$. NAc inactivation by intra-NAc infusion of the GABAa agonist muscimol (MUS, $N=5$ pairs) blocked the effects of either systemic or intra-VTA DZP on social competition in HA, while HA animals infused intra-NAc with vehicle ( $N=5$ pairs) exhibited DZP's boosting effects on social competition $(\mathbf{g}$ and $\mathbf{h})$, systemic: $t=2.74$, df $=8$, $P=0.025$; (i and $\mathbf{j})$, intra-VTA: $t=2.46, \mathrm{df}=8, P=0.039)$. Data $(\mathbf{b}, \mathbf{h}$ and $\mathbf{j})$ are mean \pm s.e.m. $\left({ }^{*} P<0.05,{ }^{*} P<0.01\right.$, unpaired Student's $t$-test). Respiration data (c, d, e and $\mathbf{f})$ are presented as estimated marginal means \pm s.e.m. of oxygen flux per mg tissue $\left({ }^{\mathrm{t}} P<0.1,{ }^{*} P<0.05, * * P<0.01\right.$, ${ }^{* * *} P<0.001$, linear mixed model). See also Supplementary Figures 11. BLA, basolateral amygdala; DZP, diazepam; HA, high-anxious; LA, lowanxious; NAc, nucleus accumbens.

equivalent contests by vehicle-treated high-anxious rats (Figure 4b). Social investigation or auto-grooming were not affected by diazepam treatment (Supplementary Table 1).

Furthermore, systemic diazepam treatment to high-anxious rats led to increased mitochondrial respiration in the NAc compared to vehicle-treated high-anxious rats (Figure 4c). Interestingly, and supporting the view of specificity for the observed effects in the NAc, the same diazepam treatment had no effect on mitochondrial respiration in the BLA (Figure 4d) or mPFC (Figure 4e). Most importantly, when high-anxious animals were tested for mitochondrial respiration 1 week after diazepam treatment, their levels did not differ from those of vehicle-treated high-anxious rats (Figure 4f), demonstrating that the effects of diazepam are transient and the mitochondrial function of diazepam-treated animals reverts to baseline with time. The enhanced mitochondrial function in the NAc in response to systemic diazepam is not restricted to high-anxious animals, as it was also observed in intermediate anxious rats (Supplementary Figures 11a and b) but not in low-anxious animals (Supplementary Figures $11 \mathrm{a}$ and $\mathrm{c}$ ).

Finally, we obtained evidence indicating that the NAc is required for the effectiveness of diazepam to increase social 
Ventral tegmental area

BASAL

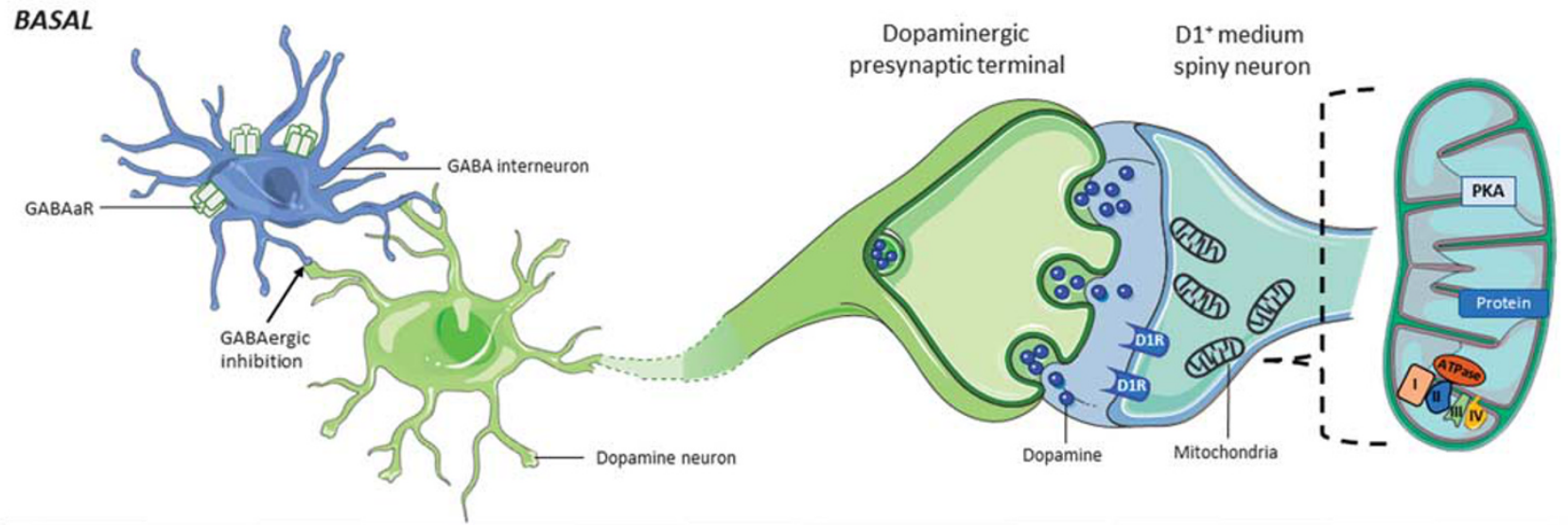

Nucleus accumbens

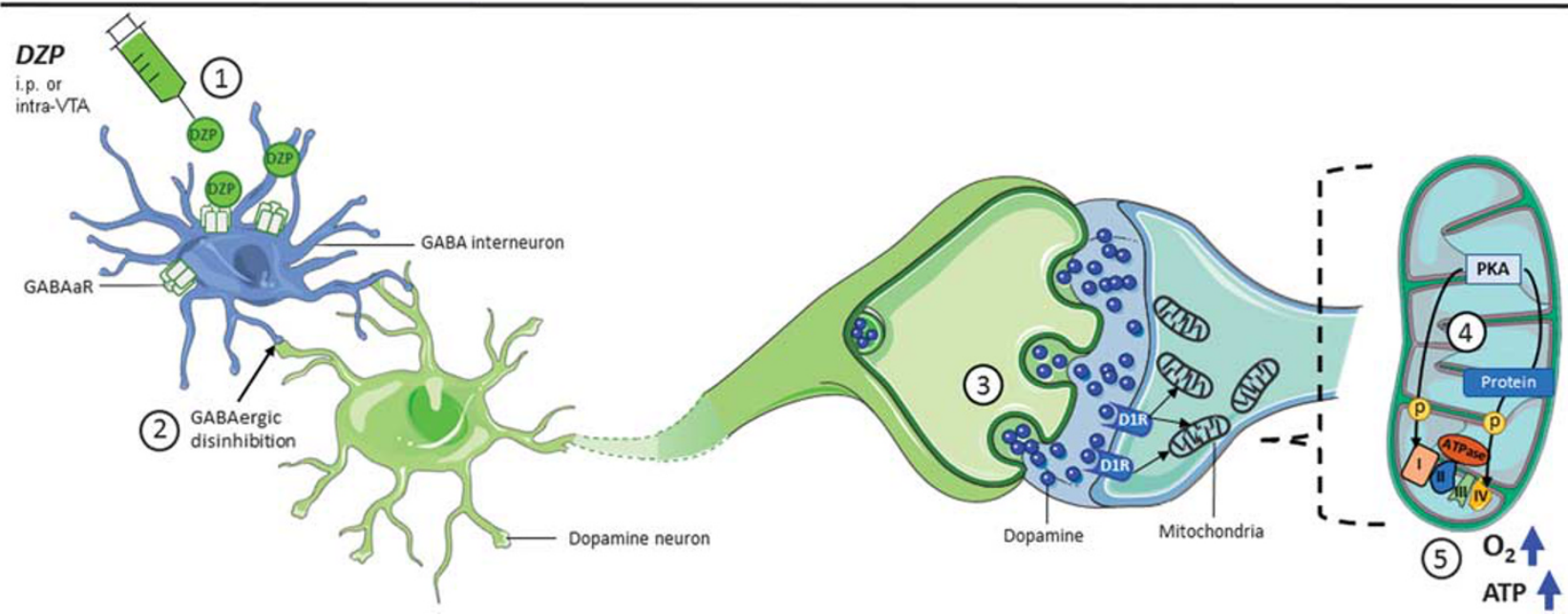

Figure 5. Hypothesized neurobiological mechanisms underlying the effects of diazepam in the VTA on mitochondrial function in the NAc. Under basal conditions (top) dopaminergic neurons in the VTA are under inhibitory control by GABAergic interneurons (in blue) thereby moderating VTA dopamine release in the NAc. Diazepam (1) binds to GABAa receptors of the VTA GABAergic interneurons causing a disinhibition of local dopaminergic neurons (2) and, thereby, resulting in enhanced dopamine release in the NAc (3). ${ }^{16}$ Then, in a dopamine D1 receptor-dependent process, mitochondrial function is enhanced. This boost in accumbal mitochondrial function, as evidenced by increased $\mathrm{O}_{2}$ respiration and elevated levels of ATP, is likely achieved through PKA-mediated phosphorylation of mitochondrial proteins that may comprise mitochondrial complex subunits ( 4 and 5 ) or other proteins. GABA, $\Upsilon$-aminobutyric acid; NAc, nucleus accumbens; VTA, ventral tegmental area.

competitiveness in high-anxious animals. Pharmacological inactivation of the NAc with muscimol ( $25 \mathrm{ng}$ per hemisphere) completely blocked the facilitating effects of both systemic (Figures $4 \mathrm{~g}$ and $\mathrm{h}$ ) and intra-VTA (Figures $4 \mathrm{i}$ and $\mathrm{j}$ ) diazepam treatment in high-anxious rats on social competition.

\section{DISCUSSION}

Benzodiazepines, the prototypic wide-spectrum anxiolytic drugs, can ameliorate social disturbances in clinical anxiety ${ }^{34}$ and facilitate social competitiveness in several species. ${ }^{10-12}$ Remarkably, the mechanisms involved in the social effects of benzodiazepines are largely unknown. Here, we identify the VTA as a major site of diazepam action on the facilitation of social dominance in rats and the NAc as a critical effector region. In the NAc, we pinpoint the causal engagement of mitochondrial function and the critical activation of D1 receptors on the facilitating effects of diazepam in social competitiveness and mitochondrial function.

Specifically, we show that low doses of diazepam administered either systemically or directly into the VTA, but not into the NAc, enhances social competitiveness. Diazepam even inverts the default submissive tendencies for high-anxious animals in their competition against low-anxious conspecifics. Our findings are in agreement with reports showing that benzodiazepines facilitate social dominance in different species, ${ }^{10,11}$ particularly in subordinate animals, ${ }^{10,12}$ and increase aggressive behavior in humans, ${ }^{35}$ particularly on high-anxious individuals. ${ }^{36}$ Note that the effects on social competence were so far reported for low doses; in fact, the opposite effect has been reported for high doses. ${ }^{37}$ This is probably related to the fact that at higher doses benzodiazepines induce sedation; an effect mediated by overstimulation of the alpha-1 type GABAa receptors. ${ }^{38}$ We also report that intra-VTA diazepam treatment enhances mitochondrial respiration in the NAc, which is in line with causal evidence implicating mitochondrial respiration in the NAc in the social rank attainment in rats. ${ }^{4}$ In addition, we show that along with the facilitation of social dominance in high-anxious rats, systemic diazepam treatment selectively increases mitochondrial respiration in the NAc, but not in the BLA or MPFC. This is in agreement with a lack of involvement of the BLA in trait anxiety-related differences in social competition and mitochondrial function. ${ }^{4}$ Critically, we present causal evidence for the involvement of 
576

mitochondrial respiration in the facilitating actions of diazepam in social competition, as reducing activation of NAc mitochondrial complex I with rotenone blocked the behavioral effects of intraVTA diazepam.

The implication of the VTA in the diazepam effects was further supported by a lack of behavioral and metabolic effects in experiments involving intra-accumbal infusion of diazepam. The identification of the VTA as a critical site of action for the effects of diazepam on social competition and mitochondrial function expands the reported role for this region in the addictive effects of benzodiazepines $^{14}$ and in the mediation of anxiety-related behaviors. ${ }^{39,40}$ VTA DA neurons project mostly to the NAC and mPFC and to a lesser extent to the hippocampus and amygdala. Here, we specifically tested and confirmed the critical involvement of the NAc in the facilitating effects of diazepam in social dominance. The relevance of the NAc in mediating intra-VTA diazepam actions is strongly supported by the activation of the NAc taking place in highly aggressive genetically selected lowanxious rats following an aggression test $\mathrm{t}^{41}$ and humans exposed to social comparison and competition. ${ }^{25,26}$

Furthermore, our findings implicate the dopaminergic system in the mediation of diazepam effects. We show that intra-VTA diazepam treatment enhances dopamine and DOPAC in the NAC and infusion of a D1, but not D2, agonist into the NAc facilitates social dominance and accumbal mitochondrial respiration. In the NAc, D1 and D2 receptors are mainly expressed at the inhibitory medium spiny neurons. Interestingly, a recent study demonstrated that enhancing the activity of D1-, but not D2-containing medium spiny neurons, promoted resilience after chronic social defeat stress. ${ }^{42}$ In line with this notion, we observed that D1-, but not D2containing cells in the NAc were activated upon intra-VTA DZP infusion. Importantly, the facilitation of social competition and accumbal mitochondrial respiration induced by intra-VTA diazepam infusion were completely blocked by antagonizing D1 receptors in the NAc. This is particularly relevant as we also show here that, compared to low-anxious animals, the competitively disadvantageous high-anxious rats display lower D1 receptor expression levels and lack of activation in D1-containing cells in the NAc following exposure to the social competition test. Although the accumbal DA system was previously shown to be engaged in social exploration ${ }^{43,44}$ and interaction, ${ }^{45}$ our findings for diazepam effects were specific for social competition as, under our experimental conditions, social exploration and autogrooming remained unaltered following intra-VTA diazepam administration. Previously, a link between anxiety and dopamine activity in the NAc was suggested; ${ }^{46-48}$ our findings confirm this link in rats and critically implicate D1-dependent actions on accumbal mitochondrial function in the behavioral effects of benzodiazepines.

Another key novel finding from our study is the involvement of D1 receptor activation in the enhancement of accumbal mitochondrial respiration. Whereas chronically high cytosolic dopamine levels, occurring under certain neuropathological conditions - such as schizophrenia or Parkinson's disease-have been suggested to impair mitochondrial function through direct interaction with the mitochondrial electron transport system, ${ }^{49,50}$ the D1-mediated effects reported here may not be directly mediated by dopamine itself but are likely to be postsynaptic and-according to our findings-presumably involve D1 signaling pathways. Notably, dopamine activation of D1 receptors stimulates cyclic AMP and PKA signaling ${ }^{51}$ and cyclic AMP and PKA phosphorylation of mitochondrial proteins regulate mitochondrial bioenergetics. Although knowledge is still scarce, emerging evidence points to a key role for extra-mitochondrial cyclic AMP on mitochondrial respiratory activity, involving mechanisms such as modulation of complex proteins from the electron transport system or phosphorylation of proteins-such as the fission protein Drp1-that regulate mitochondrial morphology. ${ }^{52}$ In particular,
PKA-mediated phosphorylation has been shown to enhance respiration ${ }^{53-55}$ and the dimerization and activity of ATP synthase, improving ATP production. ${ }^{56}$ In agreement with the potential involvement of this mechanism of action in our study, we found evidence for increased PKA-dependent protein phosphorylation in the NAc following intra-NAc infusion of DZP. Furthermore, the ERK pathway has also been involved in the mediation of converging dopamine and glutamate signals ${ }^{51}$ and ERK has recently been found to translocate not only to the nucleus but also to mitochondria. ${ }^{57}$ A full elucidation of the mechanisms by which D1 signaling modulates accumbal mitochondrial function following diazepam administration warrants future research.

High-trait anxiety provides susceptibility for the development of psychopathologies under stress $s^{6,58,59}$ and high-anxious humans as well as rats appear particularly disadvantaged in stressful competitive encounters. ${ }^{2,4}$ Previously, we demonstrated that differences in trait anxiety are related to increased mitochondrial respiration in the NAc and different expression levels of social dominance. We now show that the anxiolytic benzodiazepine diazepam reduces this anxiety and boosts social dominance. The facilitating effects of diazepam injected peripheral or infused intraVTA on mitochondrial function in the NAc presumably involve the activation of NAc D1 receptors and downstream signaling effects on mitochondrial targets (Figure 5). Although it is tempting to speculate, our findings do not automatically imply the inverse; namely that anxiety can be treated by affecting mitochondrial respiration. Here, our results demonstrate that intact mitochondrial function in the NAC is critical for the effects of diazepam on social dominance. These results strongly support a critical role for mitochondrial respiration and bioenergetics in social behavior and highlight the involvement of the NAc in social dominance. We suggest that the increased accumbal energy metabolism, as invoked by diazepam, could lead to a heightened motivational state experienced by high-anxious animals, thereby shifting their decision-making process from forfeiting to perseverance.

\section{CONFLICT OF INTEREST}

CC is an employee of the Nestlé Institute of Health Sciences SA. The remaining authors declare no conflict of interest.

\section{ACKNOWLEDGMENTS}

We thank K Meng and M-H Lu for excellent technical assistance. This work was supported by grants from the Swiss National Science Foundation (SNF, 31003A152614 and NCCR Synapsy, 51NF40-158776), SNF R'EQUIP grant No. 145004 and intramural funding from the École Polytechnique Fédérale de Lausanne. IZ was supported by an EMBO grant long-term fellowship (ALTF 1537-2015), co-funded by Marie Curie actions (LTFCOFUND2013, GA-2013-609409).

\section{AUTHOR CONTRIBUTIONS}

All authors contributed substantially to this work. MvdK performed all pharmacology experiments. $\mathrm{FH}$ and MvdK performed social dominance behavioral experiments. $\mathrm{FH}, \mathrm{CC}$ and MvdK performed mitochondrial respiration studies. LL performed pharmacological and behavioral experiments for social preference test and HPLC and assisted with intracerebral cannulations, behavioral and immunohistochemical studies. OZ, IZ and SA performed molecular experiments. JG, IG, OZ and IZ performed microdialysis and HPLC experiments. CS developed the conceptual framework and guided experimental design. CS, FH, CC and MvdK discussed the results and wrote the manuscript. MvdK and $\mathrm{FH}$ contributed equally to the study.

\section{REFERENCES}

1 Scott KM. Sex differences in the disability associated with mental disorders. Curr Opin Psychiatry 2011; 24: 331-335. 
2 Goette L, Bendahan S, Thoresen J, Hollis F, Sandi C. Stress pulls us apart: anxiety leads to differences in competitive confidence under stress. Psychoneuroendocrinology 2015; 54: 115-123.

3 Davis JF, Krause EG, Melhorn SJ, Sakai RR, Benoit SC. Dominant rats are natural risk takers and display increased motivation for food reward. Neuroscience 2009; 162: 23-30.

4 Hollis F, van der Kooij MA, Zanoletti O, Lozano L, Cantó C, Sandi C. Mitochondrial function in the brain links anxiety with social subordination. Proc Natl Acad Sci USA 2015; 112: 15486-15491.

5 Gilbert P, McEwan K, Bellew R, Mills A, Gale C. The dark side of competition: how competitive behaviour and striving to avoid inferiority are linked to depression, anxiety, stress and self-harm. Psychol Psychother 2009; 82: 123-136.

6 Sandi C, Richter-Levin G. From high anxiety to depression: a neurocognitive hypothesis. Trens Neurosci 2009; 32: 312-330.

7 Boyce WT. Social stratification, health, and violence in the very young. Ann NY Acad Sci 2004; 1036: 47-68.

8 Sapolsky RM. The influence of social hierarchy on primate health. Science 2005; 308: 648-652.

9 Marmot M. The health gap: the challenge of an unequal world. Lancet $\mathbf{3 8 6}$ 2442-2444.

10 Lovell DK, Bedford JA, Grove L, Wilson MC. Effects of d-amphetamine and diazepam on paired and grouped primate food competition. Pharmacol Biochem Behav 1980; 13: 177-181.

11 Piret B, Depaulis A, Vergnes M. Opposite effects of agonist and inverse agonist ligands of benzodiazepine receptor on self-defensive and submissive postures in the rat. Psychopharmacology (Berl) 1991; 103: 56-61.

12 Fachinelli C, Ison M, Rodríquez Echandía EL. Effects of diazepam and flumazenil on food competition behavior in high- and low-aggression pigeons. Pharmacol Biochem Behav 2003; 74: 765-770.

13 Janhsen K, Roser P, Hoffmann K. The problems of long-term treatment with benzodiazepines and related substances. Dtsch Arztebl Int 2015; 112: 1-7.

14 Tan KR, Rudolph U, Lüscher C. Hooked on benzodiazepines: GABAA receptor subtypes and addiction. Trends Neurosci 2011; 34: 188-197.

15 O'Brien DP, White FJ. Inhibition of non-dopamine cells in the ventral tegmental area by benzodiazepines: relationship to A10 dopamine cell activity. Eur J Pharmacol 1987; 142: 343-354.

16 Tan KR, Brown M, Labouèbe G, Yvon C, Creton C, Fritschy JM et al. Neural bases for addictive properties of benzodiazepines. Nature 2010; 463: 769-774

$17 \mathrm{Xi} Z \mathrm{ZX}$, Stein EA. Nucleus accumbens dopamine release modulation by mesolimbic GABAA receptors-an in vivo electrochemical study. Brain Res 1998; 798: $156-165$.

18 Robbins TW, Everitt BJ. A role for mesencephalic dopamine in activation: commentary on Berridge (2006). Psychopharmacology (Berl) 2007; 191: 433-437.

19 Salamone JD, Correa M. The mysterious motivational functions of mesolimbic dopamine. Neuron 2012; 76: 470-485.

20 Treadway MT, Buckholtz JW, Cowan RL, Woodward ND, Li R, Ansari MS et al. Dopaminergic mechanisms of individual differences in human effort-based decision-making. J Neurosci 2012; 32: 6170-6176.

21 Niv Y, Daw ND, Dayan P. Choice values. Nat Neurosci 2006; 9: 987-988.

22 Niv Y, Daw ND, Joel D, Dayan P. Tonic dopamine: opportunity costs and the control of response vigor. Psychopharmacology 2007; 191: 507-520.

23 Lüscher C, Malenka RC. Drug-evoked synaptic plasticity in addiction: from molecular changes to circuit remodeling. Neuron 2011; 69: 650-663.

24 Beeler JA, Frazier CR, Zhuang X. Putting desire on a budget: dopamine and energy expenditure, reconciling reward and resources. Front Integr Neurosci 2012; 6: 49 .

25 Zink CF, Tong Y, Chen Q, Bassett DS, Stein JL, Meyer-Lindenberg A. Know your place: neural processing of social hierarchy in humans. Neuron 2008; 58: 273-283.

26 Ly M, Haynes MR, Barter JW, Weinberger DR, Zink CF. Subjective socioeconomic status predicts human ventral striatal responses to social status information. Curr biol 2011; 21: 794-797.

27 Le Bouc R, Pessiglione M. Imaging social motivation: distinct brain mechanisms drive effort production during collaboration versus competition. J Neurosci 2013; 33: 15894-15902.

28 Morgan D, Grant KA, Gage HD, Mach RH, Kaplan JR, Prioleau O et al. Social dominance in monkeys: dopamine D2 receptors and cocaine self-administration. Nat Neurosci 2002; 5: 169-174.

29 Nader MA, Nader SH, Czoty PW, Riddick NV, Gage HD, Gould RW et al. Social dominance in female monkeys: dopamine receptor function and cocaine reinforcement. Biol Psychiatry 2012; 72: 414-421.

30 Jupp B, Murray JE, Jordan ER, Xia J, Fluharty M, Shrestha S et al. Social dominance in rats: effects on cocaine self-administration, novelty reactivity and dopamine receptor binding and content in the striatum. Psychopharmacology (Berl) 2016; 233: $579-589$.
31 Greenberg GD, Steinman MQ, Doig IE, Hao R, Trainor BC. Effects of social defeat on dopamine neurons in the ventral tegmental area in male and female California mice. Eur J Neurosci 2015; 42: 3081-3094.

32 Anstrom KK, Miczek KA, Budygin EA. Increased phasic dopamine signaling in the mesolimbic pathway during social defeat in rats. Neuroscience 2009; 161: 3-12.

33 Gong W, Neill DB, Lynn M, Justice JB. Dopamine D 1/D 2 agonists injected into nucleus accumbens and ventral pallidum differentially affect locomotor activity depending on site. Neuroscience 1999; 93: 1349-1358.

34 Blanco C, Bragdon LB, Schneier FR, Liebowitz MR. The evidence-based pharmacotherapy of social anxiety disorder. Int J Neuropsychopharmacol 2013; 16: 235-249.

35 Wallace PS, Taylor SP. Reduction of appeasement-related affect as a concomitant of diazepam-induced aggression: evidence for a link between aggression and the expression of self-conscious emotions. Aggress Behav 2009; 35: 203-212.

36 Albrecht B, Staiger PK, Hall K, Miller P, Best D, Lubman DI. Benzodiazepine use and aggressive behaviour: a systemic review. Aust N Z J Psychiatry 2014; 48 1096-1114.

37 Hebert MA, Potegal M, Moore T, Evenson AR, Meyerhoff JL. Diazepam enhances conditioned defeat in hamsters (Mesocricetus auratus). Pharmacol Biochem Behav 1996; 55: 405-413.

38 Rudolph U, Crestani F, Benke D, Brünig I, Benson JA, Fritschy JM et al. Nature 1999; 401: 796-800.

39 Kim SY, Adhikari A, Lee SY, Marshel JH, Kim CK, Mallory CS et al. Diverging neural pathways assemble a behavioural state from separable features in anxiety. Nature 2013; 496: 219-223.

40 Jennings JH, Sparta DR, Stamatakis AM, Ung RL, Pleil KE, Kash TL et al. Distinct extended amygdala circuits for divergens motivational states. Nature 2013; 496: 224-228.

41 Beiderbeck DI, Reber SO, Havasi A, Bredewold R, Veenema AH, Neumann ID. High and abnormal forms of aggression in rats with extremes in trait anxiety-involvement of the dopamine system in the nucleus accumbens. Psychoneuroendocrinology 2012; 37: 1969-1980.

42 Francis TC, Chandra, Friend DM, Finkel E, Dayrit G, Miranda J et al. Nucleus accumbens medium spiny neuron subtypes mediate depression-related outcomes to social defeat stress. Biol Psychiatry 2015; 77: 212-222.

43 Robinson DL, Heien ML, Wightman RM. Frequency of dopamine concentration transients increases in dorsal and ventral striatum during introduction of conspecifics. J Neurosci 2002; 22: 10477-10486.

44 Gunaydin L, Grosenick L, Finkelstein JC, Kauvar IV, Fenno LE, Adhikari A et al. Natural neural projection dynamics underlying social behavior. Cell 2014; 157: 1535-1551.

45 Puglisi-Allegra S, Cabib S. Psychopharmacology of dopamine: the contribution of comparative studies in strains of mice. Prog Neurobiol 1997; 51: 637-661.

46 Price JL, Drevets WC. Neurocircuitry of mood disorders. Neurpsychopharmacology 2010; 35: 191-216.

47 Corral-Frias NS, Lahood RP, Edelman-Vogelsang KE, French ED, Fellous JM Involvement of the ventral tegmental area in a rodent model of post-traumatic stress disorder. Neuropsychopharmacology 2013; 38: 350-363.

48 Yorgason JT, España RA, Konstantopoulos JK, Weiner JL, Jones SR. Enduring increases in anxiety-like behavior and rapid nucleus accumbens dopamine signaling in socially isolated rats. Eur J Neurosci 2013; 37: 1022-1031.

49 Rosenfeld M, Brenner-Lavie H, Ari SG, Kavushansky A, Ben-Shachar D. Perturbation in mitochondrial network dynamics and in complex I dependent cellular respiration in schizophrenia. Biol psychiatry 2011; 69: 980-988.

50 Jana S, Sinha M, Chanda D, Roy T, Banerjee K, Munshi S et al. Mitochondrial dysfunction mediated by quinone oxidation products of dopamine: Implications in dopamine cytotoxicity and pathogenesis of Parkinson's disease. Biochim Biophys Acta 2011; 1812: 663-673.

51 Girault JA. Signaling in striatal neurons: the phosphoproteins of reward, addiction, and dyskinesia. Prog Mol Biol Transl Sci 2012; 106: 33-62.

52 Valsecchi F, Ramos-Espiritu LS, Buck J, Levin LR, Manfredi G. CAMP and mitochondria. Physiology (Bethesda) 2013; 28: 199-209.

53 De Rasmo D, Panelli D, Sardanelli AM, Papa S. CAMP-dependent protein kinase regulates the mitochondrial import of the nuclear encoded NDUFS4 subunit of complex I. Cell signal 2008; 20: 989-997.

54 Acin-Perez R, Gatti DL, Bai Y, Manfredi G. Protein phosphorylation and prevention of cytochrome oxidase inhibition by ATP: coupled mechanisms of energy metabolism regulation. Cell metab 2011; 13: 712-719.

55 Hebert-Chatelain E, Desprez T, Serrat R, Bellocchio L, Soria-Gomez E, Busquets-Garcia $A$ et al. A cannabinoid link between mitochondria and memory. Nature 2016; 539: 555-559.

56 Gomes LC, Di Benedetto G, Scorrano L. During autophagy mitochondria elongate, are spared from degradation and sustain cell viability. Nat Cell Biol 2011; 13: 589-598. 
57 Wainstein E, Seger R. The dynamic subcellular localization of ERK: mechanisms of translocation and role in various organelles. Curr Opin Cell Biol 2016; 39: 15-20.

58 Sandi C, Cordero MI, Ugolini A, Varea E, Caberlotto L, Large CH. Chronic stress-induced alterations in amygdala responsiveness and behavior -modulation by trait anxiety and corticotropin-releasing factor systems. Eur J Neurosci 2008; 28: 1836-1848.

59 Castro JE, Diessler S, Varea E, Márquez C, Larsen MH, Cordero Ml et al. Personality traits in rats predict vulnerability and resilience to developing stress-induced depression-like behaviors, HPA axis hyper-reactivity and brain changes in pERK1/2 activity. Psychoneuroendocrinology 2012; 37: 1209-1223.

(c) (1) (2) This work is licensed under a Creative Commons AttributionSA NonCommercial-ShareAlike 4.0 International License. The images or other third party material in this article are included in the article's Creative Commons license, unless indicated otherwise in the credit line; if the material is not included under the Creative Commons license, users will need to obtain permission from the license holder to reproduce the material. To view a copy of this license, visit http:// creativecommons.org/licenses/by-nc-sa/4.0/

(c) The Author(s) 2018

Supplementary Information accompanies the paper on the Molecular Psychiatry website (http://www.nature.com/mp) 